\title{
Analysis of the Algorithm for Medical Diagnostic Reasoning based on the New Similarity measure of Fuzzy Set
}

\author{
Pranamika Kakati \\ Department of Computer Science, \\ Gauhati University, \\ Guwahati, Assam, India
}

\begin{abstract}
This article analyses the algorithm for Medical Diagnostic Reasoning based on the new Similarity measure of Fuzzy sets. The new Similarity measure is based on the fact that Fuzzy membership function and Fuzzy membership value for the complement of a Fuzzy set are two different things. In this paper, the analysis of the algorithm is carried out using Big O notation to find the order of growth for it.
\end{abstract}

\section{General Terms}

Algorithm for Medical Diagnostic Reasoning, Time Complexity

\section{Keywords}

Fuzzy set, Complement of a Fuzzy set, Fuzzy membership value, Fuzzy membership function, Fuzzy reference function, Similarity measure, Medical Diagnostic reasoning, Time Complexity.

\section{INTRODUCTION}

The most common metric for calculating time complexity is $\mathrm{Big} \mathrm{O}$ notation. Big $\mathrm{O}$ gives the upper bound for time complexity of an algorithm. The algorithm for Medical Diagnostic Reasoning is based on the extended definition of Fuzzy set introduced by Baruah[2,3,4]. According to Baruah , to define a Fuzzy set two functions namely- Fuzzy membership function and -Fuzzy reference function are necessary. Fuzzy membership value is the difference between Fuzzy membership function and Fuzzy reference function. Fuzzy membership function and Fuzzy membership value are two different things. Also Neog and Sut [4] have generalized the concept of complement of a Fuzzy set, introduced by Baruah[2,3], when the Fuzzy reference function is not zero and defined arbitrary Fuzzy union and intersection extending the definition of Fuzzy sets given by Baruah $[2,3]$. On the basis of this extended definition of complementation[2,3,4] of Fuzzy set based on reference function we have established an algorithm[13] to support Medical Diagnostic reasoning using the new Similarity measure[10,11] for Fuzzy sets together with the validation[12] of the results obtained from its application with the help of traditional Hamming Distance and Euclidean Distance measures. In this article, our aim is to find the order of growth for this algorithm using big $\mathrm{O}$ notation.

The overall organization of this paper is as follows. Section 2 overviews the new Similarity measure for Fuzzy sets based on the extended definition of complementation. In section 3 we discuss the algorithm based on the new Similarity measure to support Medical Diagnostic reasoning. We analyze the time complexity for the algorithm in section 4. Finally, some conclusions are given in section 5 .

\section{THE NEW SIMILARITY MESURE FOR FUZZY SETS}

Let $\mathrm{A}$ and $\mathrm{B}$ be two elements belonging to a Fuzzy set (or sets). Now we can measure the similarity between A and B as below:

$\operatorname{Sim}(A, B)=\frac{1_{F S}(A, B)}{l_{F S}\left(A, B^{C}\right)}==\frac{a}{b}$

where $\mathrm{a}$ is distance from $\mathrm{A}\left(\mu_{\mathrm{m}}, \mu_{\mathrm{r}}, \mu_{\mathrm{v}}\right)$ to $\mathrm{B}\left(\mu_{\mathrm{m}}, \mu_{\mathrm{r}}, \mu_{\mathrm{v}}\right)$ and $\mathrm{b}$ is a distance from $\mathrm{A}\left(\mu_{\mathrm{m}}, \mu_{\mathrm{r}}, \mu_{\mathrm{v}}\right)$ to $\mathrm{B}^{\mathrm{C}}\left(\mu_{\mathrm{m}}, \mu_{\mathrm{r}}, \mu_{\mathrm{v}}\right)$ where $\mu_{\mathrm{m}}, \mu_{\mathrm{r}}, \mu_{\mathrm{v}}$ are membership function, reference function and membership value respectively.

For this similarity measure, we have,

$$
0 \leq \operatorname{Sim}(\mathrm{A}, \mathrm{B}) \leq \propto
$$

Similarly we can calculate the Similarity between two Fuzzy sets:

Let A and B be two Fuzzy sets defined on the same set of universe of discourse. Now we can measure the similarity between A and B by assessing similarity of the corresponding elements belonging to $\mathrm{A}$ and $\mathrm{B}$, as defined in the eqn (1).

Now using Baruah's definition of Fuzzy set, for the Similarity measure of $\mathrm{A}$ and $\mathrm{B}$, we can obtain the following 4 possibilities,

A and B may be two exactly similar sets. or $\mathrm{A}$ and $\mathrm{B}^{\mathrm{C}}$ may be two exactly similar sets. or A may be more similar to $\mathrm{B}$ than to $\mathrm{B}^{\mathrm{C}}$. or $\mathrm{A}$ may be more similar to $\mathrm{B}^{\mathrm{C}}$ than to $\mathrm{B}$. But $A$ can never be similar to $B$ and $\mathrm{B}^{\mathrm{C}}$ together i.e. $\mathrm{A}=\mathrm{B}=\mathrm{B}^{\mathrm{C}}$ is never possible according to the new definition of complementation of Fuzzy set [2, 3].

Therefore from the above analysis, for the Similarity measure of A and B, we can conclude four possible cases as follows:

Case 1: $\operatorname{Sim}(A, B)=0$ when $A=B$ i.e. $A B=0$.

Case 2: $\operatorname{Sim}(A, B)=\infty$ when $A=B^{C}$ i.e. $A B^{C}=0$.

Case 3: $\operatorname{Sim}(A, B)>1$ when $A B>A B C$.

Case 4: $\operatorname{Sim}(A, B)<1$ when $A B<A B$. 
Hence to measure the similarity between the two Fuzzy sets A and $\mathrm{B}$, one should be interested in the values $0 \leq \operatorname{Sim}(\mathrm{A}, \mathrm{B})$

$<1$.

Let us explain the above idea for the new Similarity measure into details:

Let $\mathrm{A}$ and $\mathrm{B}$ be two Fuzzy sets defined on the same set of universe of discourse $\mathrm{U}=\left\{\mathrm{e}_{1}, \mathrm{e}_{2}, \mathrm{e}_{3}, \mathrm{e}_{4}, \mathrm{e}_{5}\right\}$. Now we can calculate the similarity measure for $\mathrm{A}$ and $\mathrm{B}$ assessing the similarity measure for the every corresponding elements of $\mathrm{A}$ and $B$ i.e. for the every element $\mathrm{e}_{1}, \mathrm{e}_{2}, \mathrm{e}_{3}, \mathrm{e}_{4}, \mathrm{e}_{5}$ of the set of universe of discourse $\mathrm{U}$, considered for $\mathrm{A}$ and $\mathrm{B}$. This means similarity measure for $\mathrm{A}$ and $\mathrm{B}$ has to be calculated with respect to every $\mathrm{e}_{1}, \mathrm{e}_{2}, \mathrm{e}_{3}, \mathrm{e}_{4}, \mathrm{e}_{5} \in \mathrm{U}$.

Now, based on the new definition of Fuzzy set, the similarity measure for the Fuzzy set $\mathrm{A}\left(\mathrm{e}_{\mathrm{k}}, \mathrm{k}=1,2,3,4,5\right)$ and the Fuzzy set $\mathrm{B}\left(\mathrm{e}_{\mathrm{k}}, \mathrm{k}=1,2,3,4,5\right)$ can be obtained under the 3 possible cases in the following manner:

We can visualize the Fuzzy set A $\left(\mathrm{e}_{\mathrm{k}}\right)$ and the Fuzzy set B $\left(e_{k}\right)$ in the number line in Figure 1 and Figure 2 respectively.

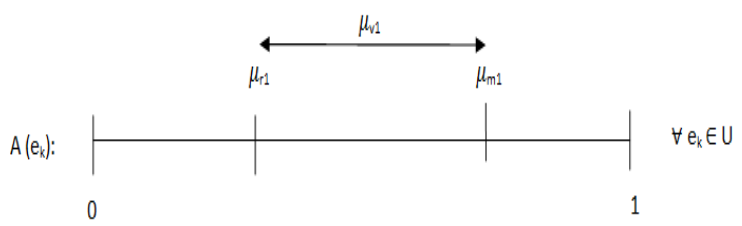

Figure 1. Representation of Fuzzy set $A\left(e_{k}\right)$ in number line

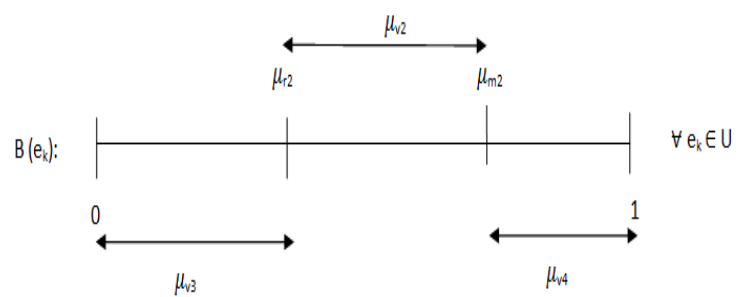

Figure 2. Representation of Fuzzy set $B\left(e_{k}\right)$ in number line

Where $\mu_{\mathrm{r} 1}, \mu_{\mathrm{m} 1}, \mu_{\mathrm{v} 1} ; \mu_{\mathrm{r} 2}, \mu_{\mathrm{m} 2}, \mu_{\mathrm{v} 2} ; 0, \mu_{\mathrm{r} 2}, \mu_{\mathrm{v} 3} ; \mu_{\mathrm{m} 2}, 1, \mu_{\mathrm{v} 4}$ are reference function, membership function and membership value of the Fuzzy set A, the Fuzzy set B and the two complement sets of $B$ respectively for every $e_{k} \in U$.

Now the 3 possible cases are:

Case 1: when $\mu_{\mathrm{r} 2} \neq 0, \mu_{\mathrm{m} 2} \neq 1$.

Case 1 can be visualized in Figure 1 and Figure 2 and Similarity Measure can be defined as,

$$
\frac{\mathrm{AB}}{\mathrm{AB}^{\mathrm{C}}}=
$$

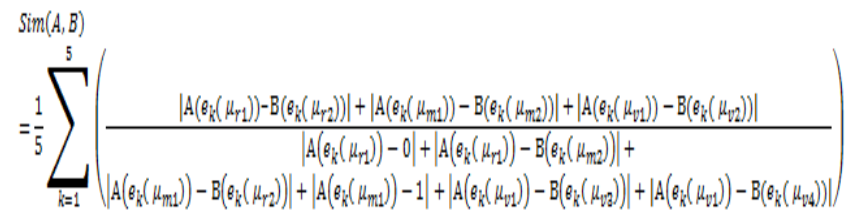

Case 2: when $\mu_{\mathrm{r} 2}=0, \mu_{\mathrm{m} 2} \neq 1$.

Case 2 can be visualized in Figure 3 and Figure 4.

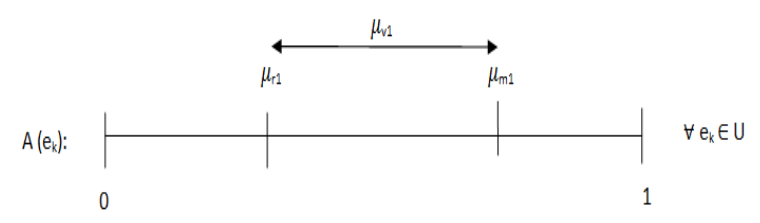

Figure 3. Representation of Fuzzy set $A\left(e_{k}\right)$ in number line

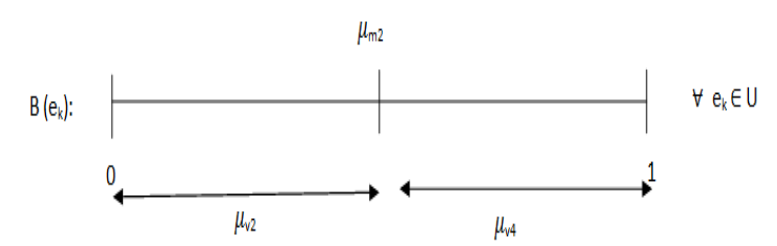

Figure 4. Representation of Fuzzy set $B\left(e_{k}\right)$ in number line

and Similarity Measure can be defined as,

$$
\begin{aligned}
& \frac{\mathrm{AB}}{\mathrm{AB}^{\mathrm{C}}}= \\
& \operatorname{sim}(A, B) \\
& =\frac{1}{5} \sum_{k=1}^{s}\left(\frac{\left|\mathrm{A}\left(e_{k}\left(\mu_{r 1}\right)\right)-0\right|+\left|\mathrm{A}\left(e_{k}\left(\mu_{m 1}\right)\right)-\mathrm{B}\left(e_{k}\left(\mu_{m 2}\right)\right)\right|+\left|\mathrm{A}\left(e_{k}\left(\mu_{v 1}\right)\right)-\mathrm{B}\left(e_{k}\left(\mu_{v 2}\right)\right)\right|}{\left|\mathrm{A}\left(e_{k}\left(\mu_{r 1}\right)\right)-\mathrm{B}\left(e_{k}\left(\mu_{m 2}\right)\right)\right|+\left|\mathrm{A}\left(e_{k}\left(\mu_{m 1}\right)\right)-1\right|+\mid \mathrm{A}\left(e_{k}\left(\mu_{v 1}\right)\right)-\mathrm{B}\left(e_{k}\left(\mu_{v 4}\right)\right)}\right)
\end{aligned}
$$

Case 3: when $\mu_{\mathrm{r} 2} \neq 0, \mu_{\mathrm{m} 2}=1$.

Case 3 can be visualized in Figure 5 and Figure 6.

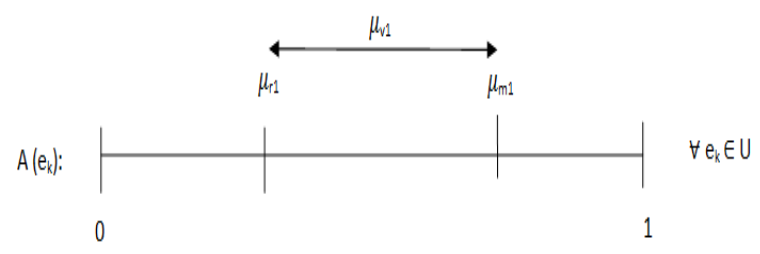

Figure 5. Representation of Fuzzy set $A\left(e_{k}\right)$ in number line

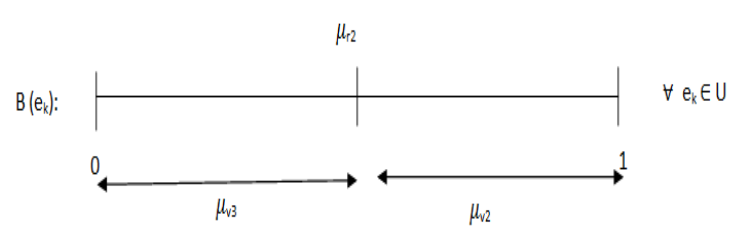

Figure 6. Representation of Fuzzy set $B\left(e_{k}\right)$ in number line and Similarity Measure can be defined as, 
$\frac{\mathrm{AB}}{\mathrm{AB}^{\mathrm{C}}}=$

$\operatorname{sim}(A, B)$
$=\frac{1}{5} \sum_{k=1}^{s}\left(\frac{\left|A\left(e_{k}\left(\mu_{r 1}\right)\right)-B\left(e_{k}\left(\mu_{r 2}\right)\right)\right|+\left|A\left(e_{k}\left(\mu_{m 1}\right)\right)-1\right|+\left|A\left(e_{k}\left(\mu_{v 1}\right)\right)-B\left(e_{k}\left(\mu_{v 2}\right)\right)\right|}{\left|A\left(e_{k}\left(\mu_{r 1}\right)\right)-0\right|+\left|A\left(e_{k}\left(\mu_{m 1}\right)\right)-B\left(e_{k}\left(\mu_{r 2}\right)\right)\right|+\left|A\left(e_{k}\left(\mu_{v 1}\right)\right)-B\left(e_{k}\left(\mu_{v 3}\right)\right)\right|}\right)$

\section{ALGORITHM FOR MEDICAL DIAGNOSTIC REASONING}

We design an algorithm on the basis of the new Similarity Measure discussed in section 2 in the following manner:

Step 1: Input Fuzzy sets $\mathrm{P}_{\mathrm{i}}$ (for Patients) and $\mathrm{D}_{\mathrm{j}}$ (for Diseases ) $\forall \mathrm{i}, \mathrm{j} \in \mathrm{Z}^{+}$

Step 2: For each $\mathrm{P}_{\mathrm{i}}$ (Patient Set)

Take each $\mathrm{D}_{\mathrm{j}}($ Disease Set $)$

and consider every $S_{k}$ (Symptom characteristics), $\mathrm{k} \in \mathrm{Z}^{+}$.

$$
\begin{aligned}
& \text { To calculate: } \operatorname{Sim}\left(\mathrm{P}_{\mathrm{i}}, \mathrm{D}_{\mathrm{j}}\right)=\frac{\mathrm{P}_{\mathrm{i}} \mathrm{D}_{\mathrm{i}}}{\mathrm{P}_{\mathrm{i}} \mathrm{D}_{\mathrm{j}}^{\mathrm{C}}} \\
& \forall \mathrm{S}_{\mathrm{k}} \in \mathrm{S} \text { ( Symptom Set) }
\end{aligned}
$$

Step 3: For each $\mathrm{P}_{\mathrm{i}}$

$$
\text { Find the smallest } \frac{\mathrm{P}_{\mathrm{i}} \mathrm{D}_{\mathrm{i}}}{\mathrm{P}_{\mathrm{i}} \mathrm{D}_{\mathrm{j}}{ }^{\mathrm{C}}} \forall \mathrm{D}_{\mathrm{j}}
$$

To determine the disease for the patient.

\section{ANALYSIS OF THE PROPOSED ALGORITHM}

Step 1: Input Fuzzy sets $\mathrm{P}_{\mathrm{i}}$ (for Patients) and $\mathrm{D}_{\mathrm{j}}$ (for Diseases ) $\forall \mathrm{i}, \mathrm{j} \in \mathrm{Z}^{+}$.

Step 1 reads fuzzy sets for patients and diseases using two different loop statements. Loops execute depending on the no. of patients and the no. of diseases inputted. Therefore the execution of each loop varies with the no. of inputs. Therefore the total run time for step 1 is $O(n)+O(n)=O(n)$.

Step 2: For each $\mathrm{P}_{\mathrm{i}}($ Patient Set $)$

Take each $D_{j}($ Disease Set)

and consider every $S_{k}$ (Symptom characteristics), $\mathrm{k} \in \mathrm{Z}^{+}$.

$$
\begin{aligned}
& \text { To calculate: } \operatorname{Sim}\left(\mathrm{P}_{\mathrm{i}}, \mathrm{D}_{\mathrm{j}}\right)=\frac{\mathrm{P}_{\mathrm{i}} \mathrm{D}_{\mathrm{i}}}{\mathrm{P}_{\mathrm{i}} \mathrm{D}_{\mathrm{j}}^{\mathrm{C}}} \\
& \forall \mathrm{S}_{\mathrm{k}} \in \mathrm{S} \text { ( Symptom Set) }
\end{aligned}
$$

Step 2 calculates Similarity measure for each patient with every diseases w.r.t. each symptom characteristics. For that step 2 uses 3 different loop statements. First loop reads the patient sets. Second loop inside the first loop reads the disease sets and the third loop inside the second loop reads the symptom characteristics. Therefore the first loop executes for total no. of patients times, second loop executes for total no. of diseases times for each patient and the third loop executes for total no. of symptom characteristics times for every disease. Thus step 2 executes for a total no. of $n * n * n=n^{3}$ times. Hence total run time for step 2 is $\mathrm{n} * \mathrm{O}(\mathrm{n}) * \mathrm{O}(\mathrm{n})=$ $\mathrm{O}\left(\mathrm{n}^{3}\right)$.
Step 3: For each $\mathrm{P}_{\mathrm{i}}$

$$
\begin{aligned}
& \text { Find the smallest } \frac{\mathrm{P}_{\mathrm{i}} \mathrm{D}_{\mathrm{i}}}{\mathrm{P}_{\mathrm{i}} \mathrm{D}_{\mathrm{j}}^{\mathrm{C}}} \forall \mathrm{D}_{\mathrm{j}} \\
& \text { To determine the disease for the patient. }
\end{aligned}
$$

Step 3 finds out the smallest value of Similarity measure for each patient among the already calculated Similarity measures with every disease in step 2. For that step 3 uses two different loop statements. The first loop represents the patient sets and the second loop inside the first loop represents the disease sets. Therefore the first loop executes for total no. of patients times and the second loop executes for total no. of disease times for each of the patient set. Thus step 3 executes for a total of $n * n=n^{2}$ times. Hence the run time for step 3 is $n *$ $\mathrm{O}(\mathrm{n})=\mathrm{O}\left(\mathrm{n}^{2}\right)$

Therefore summarizing the run times of every steps, the overall run time for the entire algorithm is $\mathrm{O}(\mathrm{n})+\mathrm{O}\left(\mathrm{n}^{3}\right)+\mathrm{O}\left(\mathrm{n}^{2}\right)=\mathrm{O}\left(\mathrm{n}^{3}\right)$.

\section{CONCLUSION}

In this article, we have focused on the new Similarity measure for Fuzzy sets based on the extended definition of complementation using reference function where it is believed that Fuzzy membership function and Fuzzy membership value for the complement of a Fuzzy set are two different things. Next, we have discussed the algorithm for Medical Diagnostic reasoning based on the new Similarity measure of Fuzzy set. Also we have analyzed the time complexity of the algorithm. Finally, it has been found that the overall runtime for the algorithm is $\mathrm{O}\left(\mathrm{n}^{3}\right)$.

\section{ACKNOWLEDGMENT}

The author would like to thank Hemanta K. Baruah, Vice Chancellor, Bodoland University, Kokrajhar, Assam for his valuable suggestions and guidance, in preparing this article.

\section{REFERENCES}

[1] L.A.Zadeh, "Fuzzy Sets" , Information and Control, 8, pp. 338-353, 1965.

[2] Hemanta K. Baruah, "Towards Forming A Field Of Fuzzy Sets" International Journal of Energy, Information and Communications, Vol.2, Issue 1, pp. 16-20, February 2011.

[3] Hemanta K. Baruah, "The Theory of Fuzzy Sets: Beliefs and Realities", International Journal of Energy, Information and Communications, Vol. 2, Issue 2,pp. 122, May,2011.

[4] Tridiv Jyoti Neog, Dusmanta Kumar Sut, "Theory of Fuzzy Soft Sets from a New Perspective", International Journal of Latest Trends in Computing, Vol. 2, No 3, September,2011.

[5] Eulalia Szmidt, Janusz Kacprzyk, "Medical Diagnostic Reasoning Using a Similarity Measure for Intuitionistic Fuzzy Sets" Eighth Int. Conf. on IFSs, Varna, 20-21 June 2004, NIFS Vol. 10 (2004), 4, 61-69.

[6] Hong-mei Ju , Feng-Ying Wang, "A Similarity Measure for Interval -valued Fuzzy Sets and Its Application in Supporting Medical Diagnostic Reasoning", The Tenth International Symposium on Operation Research and Its Applications(ISORA 2011), Dunhuang, China, August 28-31, 2011. 
[7] Szmidt E., Kacprzyk J. (2001), "Entropy for intuitionistic Fuzzy sets". Fuzzy Sets and Systems, vol. 118, No. 3, pp. 467-477.

[8] Hongmei Ju (2008). "Entropy for Interval-valued Fuzzy Sets",Fuzzy information and engineering, Volume 1,358366.

[9] Kasuba , Tom(1993), Simplified Fuzzy ARTMAP, AI Expert, November, pp.18-25.

[10] Pranamika Kakati (2013). "A Study on Similarity Measure for Fuzzy Sets" International Journal of Advanced Research in Computer Science and Softaware Engineering, vol. 3 Issue 8, pp.97-103, August 2013.

[11] Pranamika Kakati (2013) "A New Similarity Measure for Fuzzy Sets with the Extended Definition of Complementation 'International Journal of Soft Computing and Engineering, Volume 3 Issue 4, pp.203207, September, 2013.

[12] Pranamika Kakati (2013) "A Note on the New Similarity Measure for Fuzzy sets" International Journal of
Computer Applications Technology and Research, Volume 2 Issue 5, pp.601-605, September-October, 2013.

[13] Pranamika Kakati (2013) "The New Similarity Measure for Fuzzy Sets and Its application to Medical Diagnostic Reasoning" International Journal of Computer Application, Volume 80- No 15, pp. 13-17, October 2013.

[14] Pranamika Kakati (2013) "A New Architecture of Simplified Fuzzy ARTMAP with the Extended Definition of Complementation" International Journal of Computer Technology and Applications, Volume 4 Issue 5, pp. 772-784, September-October, 2013.

[15] Pranamika Kakati, Hemanta K. Baruah (2013) "The New Architecture of Simplified Fuzzy ARTMAP for Supporting Medical Diagnostic Reasoning” International Journal of Computer Application, Volume 81- No 17, pp. 16-19, November 2013. 